\title{
Rapid detection of Listeria monocytogenes in dairy samples utilizing a PCR-based fluorogenic $5^{\prime}$ nuclease assay
}

\author{
T Cox , C Frazier , J Tuttle , S Flood , L Yagi , CT Yamashiro , R Behari , C Paszko and RJ Cano
}

\begin{abstract}
The presence of Listeria monocytogenes as a dairy food contaminant is a lethal threat to dairy industrialists; therefore, products tainted with $L$. monocytogenes must be quickly detected and removed from production. This fluorogenic PCR-based assay was developed to rapidly detect $L$. monocytogenes contamination in dairy samples before a final product is distributed. The detection method employed uses a PCR primer pair and a fluorogenic TaqMan probe which bind to a region of a virulence determinant gene specific to $L$. monocytogenes. As the DNA target is amplified, the $5^{\prime}$ nuclease activity of Taq DNA polymerase hydrolyzes the internal fluorogenic probe creating a change in fluorescence that can be monitored and automatically analyzed with a fluorometer. Sensitivity studies indicated a lower detection limit of under $10 \mathrm{CFU}$ for pure culture extracts and spiked dairy enrichments. A study was performed on 266 dairy product samples obtained from Central California dairy production plants. Eighty-three of these samples were artificially spiked with both high and low concentrations of L. monocytogenes before an overnight enrichment in TSB/LiCl/colostin sulfate/moxalactam media. DNA from enriched samples was obtained using a rapid Chelex extraction specifically designed for dairy sample enrichments and automated analysis. The extraction was followed by the fluorogenic PCR assay and measurement of fluorescence increase. The assay was completed within $24 \mathrm{~h}$, with an observed $95.2 \%$ sensitivity, $96.7 \%$ specificity, $92.9 \%$ positive predictive value, $97.8 \%$ negative predictive value, and $96.2 \%$ accuracy. According to specificity studies, five other bacterial species crossreacted with the fluorogenic $5^{\prime}$ nuclease PCR. However, only one of these strains (Listeria grayi) was able to grow in the enrichment medium employed, and was not isolated from any of the $\mathbf{2 6 6}$ dairy product enrichments evaluated in this study. Therefore, this method provides a rapid, sensitive, and automatable analysis alternative to standard culture techniques for the detection of Listeria monocytogenes in dairy samples.
\end{abstract}

\section{Introduction}

Listeria monocytogenes is a Gram-positive, facultatively anaerobic food-borne pathogen which has emerged as a disease agent of substantial public health concern. Listerial infections are primarily opportunistic and particularly dangerous to immunocompromised persons, pregnant women, the elderly, and newborns [18]. Ingestion of food contaminated with Listeria monocytogenes can result in septicemia, meningitis, meningoencephalitis, abortion, and death. Dairy products, such as pasteurized milk and soft cheeses, have been shown to be major vehicles of contamination during several Listeria monocytogenes outbreaks which reached epidemic proportion [18]. Because of Listeria's wide distribution in nature and its ability to proliferate at refrigeration temperatures, it is especially threatening to the dairy industry if fast and reliable detection methods are not employed.

Classical methods of detecting L. monocytogenes in food and dairy samples involve selective enrichments with subsequent culturing on selective media, followed by serological and/or biochemical species identification. This process takes a minimum of 5 days to confirm a sample free of Listeria, and about 10 days to characterize to the species level [15]. Polymerase chain reaction technology has significantly reduced the detection time for pathogen identification in food and dairy products [3]. Direct PCR-based detection methods have been described for Listeria monocytogenes [6,13]; however, pre-enrichment procedures are still necessary for assurance of detection of low numbers of viable cells in foods and dairy products [11].

If a 24-h detection method is preferred, total analysis time for DNA extraction and PCR detection methods in high-throughput volumes must be within approximately 4-5 h after a 19-20 h enrichment process. Fluorescence technology has aided in significantly decreasing post-PCR analysis time by replacing gel electrophoresis steps for PCR product detection [4,14]. Amplification products can be detected directly by measuring fluorescence increases due to ethidium bromide intercalation of double-stranded DNA [4], or by utilizing a 5' nuclease activity in conjunction with a fluorogenic probe for monitoring DNA amplification [14].

Fluorogenic PCR-based assays employing the 5' nuclease activity of Taq DNA polymerase have been described and applied to the detection of Listeria monocytogenes pure cultures, Shiga-like toxin producing E. coli, and Salmonella $[1,5,19]$. The assay utilizes the $5^{\prime}$ nuclease activity of Taq DNA polymerase to hydrolyse an internal fluorogenic probe during the PCR amplification process. The TaqMan probe is doubly labeled with both a reporter dye and quencher 
dye, and hybridizes to an internal region within the amplicon. When the probe is intact, the quencher dye reduces the emission intensity of the reporter dye. As the DNA target is amplified during the extension cycle of the reaction, the 5' nuclease activity of Taq DNA polymerase hydrolyzes the internal fluorogenic probe. The separation of the dyes due to probe hydrolysis allows an increase in reporter dye emission proportional to DNA amplification [14].

We describe the development of a rapid, high throughput fluorogenic $5^{\prime}$ nuclease assay for the detection of Listeria monocytogenes in dairy samples. Selective enrichment and DNA extraction protocols were specifically developed and evaluated for use with the TaqMan LS-50B PCR Detection System. Studies were conducted to evaluate the specificity and sensitivity of the assay with both pure cultures and dairy sample enrichments. Performance of the assay was then assessed with 266 dairy samples encompassing a broad range of dairy sample types.

\section{Materials and methods}

\section{Bacterial strains}

Bacterial cultures used for spiking, sensitivity, and specificity testing were obtained from the following sources: American Type Culture Collection (ATCC), Rockville, MD; Centers for Disease Control (CDC), Atlanta, GA; PE Applied Biosystems, Foster City, CA; United States Department of Agriculture (USDA), Athens, GA; Department of Health Services, Berkeley, CA; and Dairy Food Laboratories (DFL), Modesto, CA.

\section{Dairy samples and enrichment procedures}

Two hundred and sixty-six dairy samples were obtained from the Dairy Products Technology Center at California Polytechnic State University, and from another undisclosed California dairy facility. The dairy samples analyzed included butter, buttermilk, raw milk, condensed whole milk, condensed skim milk, pasteurized milk, chocolate milk, cheese, cottage cheese, yogurt, whey, and ice cream. Upon arrival of the dairy samples at the laboratory, $1 \mathrm{~g}$ or $1 \mathrm{ml}$ of each sample was aseptically transferred to $9 \mathrm{ml}$ of enrichment broth (per liter: $30 \mathrm{~g}$ Trypticase Soy Broth (TSB) (Acumedia, Baltimore, MD, USA), $10 \mathrm{~g} \mathrm{LiCl,} 5$ g yeast extract, $0.0025 \mathrm{~g}$ colostin sulfate, and $0.005 \mathrm{~g}$ moxolactam (TSB-LCM). A preliminary study evaluating several culture media indicated that this enrichment formulation was the most effective and selective media for use with Listeria monocytogenes and this particular assay (unpublished data). Selected enrichments were spiked as positive controls and sensitivity studies with varying amounts (approximately 1 to $1 \times 10^{8} \mathrm{CFU}$ ) of L. monocytogenes Scott A. Overnight cultures of $L$. monocytogenes Scott A grown in TSB were serially diluted and enumerated by viable culture (pour plate enumeration). Spiking of dairy enrichments before incubation was performed utilizing various dilutions of the enumerated L. monocytogenes cultures to evaluate the sensitivity of the assay. These enrichments utilized $25 \mathrm{~g}$ of dairy sample in $225 \mathrm{ml}$ of enrichment broth. All enrichments were incubated a standard $20 \mathrm{~h}$ in an incubator-shaker at $37^{\circ} \mathrm{C}$ and $200 \mathrm{rpm}$.
After enrichment, dairy samples were streaked onto Modified Oxford (MOX) (Difco Laboratories, Detroit, MI, USA) plates and DNA was extracted from $1.5 \mathrm{ml}$ of the culture. Cultures that exhibited positive esculin hydrolysis reactions on MOX plates after $24 \mathrm{~h}$ at $37^{\circ} \mathrm{C}$, were isolated and identified by fatty acid methyl ester analysis (FAME) (MIDI, Newark, NJ, USA).

\section{DNA extractions}

All pure cultures used for specificity testing were extracted utilizing a modified microwave DNA extraction procedure [12]. DNA quantification was performed by comparing DNA extracts to dilutions of quantified lambda phage DNA on $1.5 \%$ agarose gels. All pure culture DNA extracts were then standardized to a concentration of approximately 1-10 ng $\mu \mathrm{l}^{-1}$.

Several variations of three types of rapid DNA extractions for dairy product enrichments were evaluated for their specific performance in conjunction with the fluorogenic $5^{\prime}$ nuclease assay format [8]. The DNA extraction methods evaluated included variations of the following methods: a modified guanidinium isothiocyanate/silica (GuSCN) procedure $[2,4]$, a Chelex ${ }^{\circledR} 100$ (BioRad, Hercules, CA, USA) DNA extraction method [9], and the EnviroAmp ${ }^{\circledR}$ Sample Preparation Kit (PE Applied Biosystems, Foster City, CA, USA). The extraction methods were tested on dairy product enrichments (including raw milk, whole milk, feta cheese, and queso blanco cheese) and evaluated for sensitivity, reliability, and ease of use when coupled with the fluorogenic 5' nuclease assay [8]. For each extraction variation, six samples of each food type were tested. Four of these six food enrichments were spiked with $10^{3}-10^{6} \mathrm{~L}$. monocytogenes CFU directly before DNA extraction, while the other two samples were left as negative controls. All enrichments were streaked onto MOX plates after spiking for culture comparison.

After assessment of the eight DNA extraction methods, the most reliable and sensitive method was chosen for a field study conducted on 266 dairy samples run through the developed assay. An additional modification of the preferred extraction method (using the Spin Filter ${ }^{\circledR}$, Bio 101, Vista, CA, USA) was used when it was found to significantly decrease background fluorescence and PCR inhibition in the extracts. The following modified Chelex ${ }^{\circledR} 100$ DNA extraction method was chosen for the field study. A 1.5-ml aliquot of the enriched dairy sample was transferred to a 1.5-ml microfuge tube with screw cap and rubber o-ring (National Scientific, San Rafael, CA, USA), then centrifuged at maximum speed to pellet bacteria. The supernatant phase was carefully removed and discarded. The pellet was resuspended in $95 \mu \mathrm{l}$ of TE buffer $\mathrm{pH} 8.0$ with gentle vortexing. Several dry lysozyme grains were added with a pipette tip, and samples were vortexed briefly, then incubated at room temperature for $20 \mathrm{~min}$. Five microliters of $20 \mathrm{mg} \mathrm{ml}^{-1}$ proteinase K (Boehringer Mannheim, Indianapolis, IN, USA) were added and samples were incubated an additional $10 \mathrm{~min}$ in a $55^{\circ} \mathrm{C}$ water bath. Next, $75 \mu \mathrm{l}$ of $20 \%$ Chelex $^{\circledR} 100$ (BioRad) matrix was added with vortexing for $1 \mathrm{~min}$. Extractions were placed in a boiling water bath for $10 \mathrm{~min}$, then set in ice for $5 \mathrm{~min}$ to cool. After briefly vortexing the mixture, the entire contents of the 
extraction tube were transferred to a Bio 101 Spin Filter ${ }^{\circledR}$ and centrifuged for $5 \mathrm{~min}$ at $14500 \times \mathrm{g}$. Filter apparatuses were removed and discarded, and the DNA was stored at $-20^{\circ} \mathrm{C}$ until further analysis.

\section{PCR conditions and fluorogenic 5 ' nuclease assay analysis}

Dairy sample DNA extracts were used as the template for PCR reactions using primers that amplify a 210-bp sequence of a virulence determinant gene specific to $L$. monocytogenes (PE Applied Biosystems). A doubly labeled internal fluorogenic TaqMan probe (PE Applied
Biosystems) also specific for this gene, was used to facilitate amplification detection during the 5' nuclease assay. The probe labeled with both a reporter dye (FAM-fluorescein derivative) and quencher dye (TAMRA-rhodamine derivative), anneals between the primers and is cleaved by the endonuclease activity of Taq polymerase during the extension cycle of PCR. Cleavage of the probe allows for the reporter dye (FAM) to be released from close proximity of the quencher dye (TAMRA) on the probe. This causes a detectable reporter dye fluorescence increase brought on by PCR amplification of the target sequence. Disposable 96-well optical reaction plates (PE Applied Biosystems)

Table 1 Specificity of the Listeria monocytogenes fluorogenic 5’ nuclease assay

\begin{tabular}{|c|c|c|c|c|c|}
\hline Microrganism & Source(s) & $\begin{array}{c}\text { Number of } \\
\text { strains tested }\end{array}$ & $\begin{array}{c}\text { Fluorescent } 5^{\prime} \\
\text { nuclease assay } \\
\text { results }\end{array}$ & $\begin{array}{c}\Delta \mathrm{RQ} \\
(>2.4=\text { positive })\end{array}$ & $\begin{array}{l}\text { Growth in } \\
\text { enrichment } \\
\text { medium? }\end{array}$ \\
\hline L. monocytogenes & PE/ABD, DHS & 19 & Positive & $9.013^{b}$ & Yes \\
\hline L. murrayi & CDC & 1 & Negative & 1.226 & Yes \\
\hline L. ivanovii & CDC & 1 & Negative & 1.930 & Yes \\
\hline L. grayi $^{\mathrm{a}}$ & CDC & 1 & Positive & 7.127 & Yes \\
\hline L. innocua & DFL & 8 & Negative & $1.618^{\mathrm{b}}$ & Yes \\
\hline L. seeligeri & $\mathrm{PE} / \mathrm{ABD}$ & 2 & Negative & $1.062^{\mathrm{b}}$ & Yes \\
\hline L. welshimeri & $\mathrm{PE} / \mathrm{ABD}$ & 2 & Negative & $1.578^{\mathrm{b}}$ & Yes \\
\hline Aeromonas hydrophila & ATCC & 1 & Negative & 1.298 & No \\
\hline Agrobacter tumefaciens & ATCC & 1 & Negative & 0.091 & No \\
\hline Alcaligenes faecalis & ATCC & 1 & Negative & 0.157 & Yes \\
\hline Azotobacter chroococcum & ATCC & 1 & Negative & 1.661 & No \\
\hline Bacillus cereus & ATCC & 2 & Negative & $0.066^{\mathrm{b}}$ & Yes \\
\hline Bacillus coagulans & ATCC & 1 & Negative & 0.480 & Yes \\
\hline Bacillus licheniformis & ATCC & 1 & Negative & -0.304 & Yes \\
\hline Bacillus megaterium & ATCC & 1 & Negative & 1.914 & No \\
\hline Bacillus polymyxa & ATCC & 1 & Negative & -0.139 & No \\
\hline Bacillus pumilus & ATCC & 1 & Negative & 0.474 & Yes \\
\hline Bacillus stearothermophilis & ATCC & 1 & Positive & 4.440 & No \\
\hline Bacillus subtilis & ATCC & 3 & Negative & $0.350^{\mathrm{a}}$ & Yes \\
\hline Bacillus thuringiensis & ATCC & 1 & Positive & 7.389 & No \\
\hline Citrobacter freundii & ATCC & 1 & Negative & -0.325 & Yes \\
\hline Corynebacterium xerosis & ATCC & 1 & Negative & 0.445 & No \\
\hline Enterobacter aerogenes & ATCC & 1 & Negative & -0.476 & No \\
\hline Enterobacter cloacae & ATCC & 1 & Negative & 0.436 & Yes \\
\hline Enterobacter hafniae & ATCC & 1 & Negative & 0.656 & Yes \\
\hline Erwinia carotovra & ATCC & 1 & Negative & 0.309 & No \\
\hline Klebsiella pneumoniae & ATCC & 1 & Negative & 0.371 & No \\
\hline Lactobacillus acidophilus & ATCC & 1 & Negative & 1.758 & No \\
\hline Lactobacillus arabinosis & ATCC & 1 & Negative & 0.572 & No \\
\hline Lactobacillus bulgaricus & ATCC & 1 & Negative & 0.073 & No \\
\hline Lactobacillus casei & ATCC & 1 & Positive & 3.214 & No \\
\hline Leuconostoc dextranicum & ATCC & 1 & Negative & 2.015 & No \\
\hline Micrococcus luteus & ATCC & 1 & Negative & 1.578 & No \\
\hline Proteus mirabilis & ATCC & 1 & Negative & -0.173 & Yes \\
\hline Proteus vulgaris & ATCC & 1 & Negative & 0.104 & No \\
\hline Providencia spp & ATCC & 1 & Negative & -0.101 & Yes \\
\hline Pseudomonas fluorescens & ATCC & 1 & Negative & 0.901 & No \\
\hline Salmonella dublin & ATCC & 1 & Negative & -0.401 & No \\
\hline Salmonella enterica & ATCC & 1 & Negative & -0.477 & No \\
\hline Serratia marcesens & ATCC & 1 & Negative & 0.091 & No \\
\hline Shigella flexneri & ATCC & 1 & Negative & 0.278 & No \\
\hline Shigella sonni & ATCC & 1 & Negative & -0.422 & No \\
\hline Staphylococcus aureus & ATCC & 1 & Positive & 4.414 & No \\
\hline Staphylococcus epidermis & ATCC & 1 & Negative & 1.620 & No \\
\hline Staphylococcus saprophyticus & ATCC & 1 & Negative & 0.140 & No \\
\hline Staphylococcus agalactiae & ATCC & 1 & Negative & 1.390 & No \\
\hline Streptococcus faecalis & ATCC & 1 & Negative & -0.093 & No \\
\hline Streptococcus hominis & ATCC & 1 & Negative & -0.255 & No \\
\hline Streptococcus lactis & ATCC & 1 & Negative & -1.030 & No \\
\hline
\end{tabular}

'andicates organism that both cross-reacts with the primer and probe in the fluorescent $5^{\prime}$ nuclease assay, and grows in the selective enrichment media. ${ }^{\mathrm{b}}$ Average $\Delta \mathrm{RQ}$ values were reported for all strains tested. 
were used for both thermal cycling and fluorescence readings. Each reaction included $5 \mu \mathrm{l}$ of DNA extract and $45 \mu \mathrm{l}$ of TaqMan Listeria monocytogenes master mix containing buffer, $\mathrm{MgCl}_{2}$, AmpliTaq DNA polymerase, dNTPs, Listeria monocytogenes specific primers, and fluorogenic TaqMan probe.

Pre-reads of samples were conducted on the TaqMan LS50B PCR Detection System (PE Applied Biosystems) to obtain baseline fluorescence for all samples and controls. Each set of samples run on a 96-well reaction plate included one TE buffer autozero control, three no amplification controls, three no template controls, and three positive controls with L. monocytogenes DNA. Reactions were cycled at $95^{\circ} \mathrm{C}$ for $5 \mathrm{~min}$, and 40 cycles of $95^{\circ} \mathrm{C}$ for $20 \mathrm{~s}, 60^{\circ} \mathrm{C}$ for $1 \mathrm{~min}$, and $72^{\circ} \mathrm{C}$ for $30 \mathrm{~s}$. Thermal cycling was performed using a GeneAmp PCR System 9600 (PE Applied Biosystems). After PCR, the 96-well reaction plate was placed in the TaqMan LS-50B PCR Detection System for post-reads of fluorescence increase.

Both pre- and post-readings of fluorescence were measured on the TaqMan LS-50B PCR Detection System so that any inherent fluorescence within samples could be subtracted out of final calculations. These were noted as normalized fluorescence values. These data were then entered into an Excel (Microsoft Corporation, Redmond, WA, USA) spreadsheet that calculated first the normalized reporter (FAM) signal/normalized quencher (TAMRA) signal $\left(\mathbf{R} \mathbf{Q}^{+}\right)$. This value was further used for calculations that subtracted out the average normalized fluorescence reading of the no template controls $\left(\mathbf{R} \mathbf{Q}^{-}\right)$. This produced what is known as the $\mathbf{R Q}$ value used to score a sample as positive or negative. The equation is:

$$
\mathbf{R Q}^{+}-\mathbf{R} \mathbf{Q}^{-}=\mathbf{R} \mathbf{Q} \text {. }
$$

\section{Gel electrophoresis}

All PCR reactions were run on $2 \%$ agarose gels, stained with ethidium bromide, and visualized with a UVP ImageStore 5000 (UVP, San Gabriel, CA, USA). Comparisons were made to TaqMan LS-50B PCR Detection System positive fluorescence determinations to the presence or absence of an amplification product visualized by gel electrophoresis.

\section{Specificity and sensitivity studies}

Specificity studies were performed with the Listeria monocytogenes fluorogenic $5^{\prime}$ nuclease assay utilizing DNA extracted from 45 non-Listeria spp common to dairy samples, 15 Listeria spp other than L. monocytogenes, and 19 L. monocytogenes strains (Table 1). All species were tested for PCR cross-reactivity to the $L$. monocytogenes primer and probe with 5-50 ng of DNA/reaction utilizing the described thermal cycling parameters. Specificity tests were also performed on the developed TSB-LCM enrichment medium. Ten-milliliter test tubes of TSB-LCM were spiked with $>100000$ CFU of each of the 45 non-Listeria spp, 15 Listeria spp, and 19 L. monocytogenes spp listed in Table 1 . The cultures were then incubated at $37^{\circ} \mathrm{C}$ for $22 \mathrm{~h}$ with shaking at $200 \mathrm{rpm}$, and evaluated for growth by optical density readings at $600 \mathrm{~nm}$. Cultures with optical density readings over. 0.01 at $600 \mathrm{~nm}$ after $22 \mathrm{~h}$ were considered positive for growth in TSB-LCM.
Sensitivity studies were performed by spiking dairy enrichments with enumerated, serially diluted L. monocytogenes, and processing these samples through the fluorogenic $5^{\prime}$ nuclease assay. Twenty-five grams of dairy sample were enriched in $225 \mathrm{ml}$ of TSB-LCM medium. Enrichments were incubated at $37^{\circ} \mathrm{C}$ for $20 \mathrm{~h}$, followed by DNA extraction, PCR, and fluorescence detection with the TaqMan LS-50B PCR Detection System. Sensitivity studies utilizing pure cultures of $L$. monocytogenes Scott A were also performed to identify the lower detection limit of the fluorescent 5' nuclease assay. L. monocytogenes Scott A cultures were grown overnight, serial diluted, enumerated, DNA extracted by Chelex ${ }^{\circledR} 100$ methodology, and run through the fluorogenic $5^{\prime}$ nuclease assay.

\section{Fatty acid methyl ester (FAME) analysis}

Fatty acid methyl ester (FAME) analysis was performed on all isolates from MOX plates that produced the characteristic black precipitate formed by esculin-hydrolysis. Isolated colonies were streaked onto TSBA (BBL, Cockeysville, MD, USA) plates and grown at $28^{\circ} \mathrm{C}$ for $24 \mathrm{~h}$ [16]. Approximately $50 \mathrm{mg}$ of wet cell weight was harvested and extracted according to standard operating procedures of MIDI [16]. The MIDI microbial identification system (MIDI, Newark, NJ, USA) was used for separation, detection, and identification of the fatty acids in the cell extracts. The system included a Hewlett-Packard 6890 Series Gas Chromatograph unit equipped with a split/splitless injector, flame ionization detector, a $25 \mathrm{~m} \times 0.2 \mathrm{~mm}$ Ultra 2 capillary column (Hewlett Packard, Palo Alto, CA, USA), autosampler, and computer system with the Sherlock software (MIDI, Newark, NJ, USA). All parameters, settings, and procedures were followed as recommended by the MIDI training manual. Fatty acid profiles obtained were compared to a standard aerobe library (MIDI) used with the Sherlock (MIDI) software system. The profiles of the unknown organisms were compared to known library profiles, generating similarity indices for each unknown.

\section{Results}

DNA extractions

DNA extraction studies were conducted to evaluate variations of three different methods (Chelex ${ }^{\circledR} 100$, GuSCN, and EnviroAmp ${ }^{\circledR}$ ) for their performance when coupled with the fluorogenic 5' nuclease assay [8]. These extraction methods were selected because they were rapid and known to be effective for DNA extraction of $L$. monocytogenes from dairy enrichments [4,5]. Table 2 summarizes the results for each extraction method evaluated. Positive and negative predictive values were calculated from the results of 24 dairy samples tested with each procedure. Lower detection limits in CFU were also derived (data not shown) to resolve the most efficient DNA extraction protocol for use with this fluorogenic $5^{\prime}$ nuclease assay [8]. As Table 2 and sensitivity data indicate, Chelex ${ }^{\circledR} 100$ Method 1 and EnviroAmp $^{\circledR}$ Method 1 gave the highest percentages of positive and negative predictive values (100\%), with similar sensitivities (data not shown) [8]. Since these two methods were identical in performance, other factors such as ease of use, cost, and toxicity influenced the decision of 
Table 2 Positive and negative predictive values for evaluated DNA extraction methods

\begin{tabular}{lccc}
\hline $\begin{array}{l}\text { Extraction } \\
\text { method } \\
{[8]}\end{array}$ & $\begin{array}{c}\text { Number of dairy } \\
\text { enrichment } \\
\text { samples tested }\end{array}$ & $\begin{array}{c}\text { Positive } \\
\text { predictive } \\
\text { value (\%) }\end{array}$ & $\begin{array}{c}\text { Negative } \\
\text { predictive } \\
\text { value (\%) }\end{array}$ \\
\hline Chelex 1 & 24 & 100 & 100 \\
Chelex 2 & 24 & 100 & 88.9 \\
Chelex 3 & 24 & 100 & 88.9 \\
GuSCN 1 & 24 & 100 & 72.7 \\
GuSCN 2 & 24 & 100 & 72.7 \\
GuSCN 3 & 24 & 100 & 100 \\
Env. Amp 1 & 24 & 100 & 100 \\
Env. Amp 2 & 24 & 94.1 & 100 \\
\hline
\end{tabular}

${ }^{a}$ DNA extraction method chosen for field study.

which method was chosen. Taking all variables into consideration, the Chelex ${ }^{\circledR} 100$ Method 1 was selected for use with this fluorogenic $5^{\prime}$ nuclease assay.

In an attempt to lower PCR inhibition with complex dairy enrichments, a step involving filtration through a Spin Filter $^{\circledR}$ (Bio 101) was added in the last step of the Chelex ${ }^{\circledR}$ 100 extraction protocol. In studies involving the analysis of samples with and without the Spin Filter ${ }^{\circledR}$ step, extracts were found to have a significant reduction in PCR inhibition when the step was incorporated (unpublished data).

\section{Specificity and sensitivity studies}

The specificity of the assay was evaluated with $19 \mathrm{~L}$. monocytogenes, 15 Listeria spp, and 45 non-Listeria strains as summarized in Table 1 . All 19 of the L. monocytogenes strains tested positive with the assay, showing high fluorescence increases and RQ values averaging 9.013 (Table 1 ). Some cross-reaction of the primer pair and fluorescent probe did occur with five of the 60 non- $L$. monocytogenes strains evaluated. Four of these strains, however, were unable to grow in the selected enrichment formulation within $24 \mathrm{~h}$ (Table 1). Only one strain that showed a primer/probe cross-reaction (Listeria grayi) was able to proliferate in the selective enrichment medium within $24 \mathrm{~h}$ and therefore could theoretically cause a false positive result for the assay (Table 1 ).

Sensitivity studies were performed on pure cultures of L. monocytogenes to test the lower detection limit of the fluorogenic 5' nuclease assay, and to verify baseline threshold RQ values for positive calls from dairy enrichments. When pure cultures of $L$. monocytogenes were enumerated and run through the DNA extraction and fluorogenic 5' nuclease assay, a lower detection limit of 2.5 CFU per PCR was obtained. This value was calculated by noting the number of CFU in the lowest dilution of culture that produced a significant increase in fluorescence over the no template controls (PCR amplification was verified by agarose gel electrophoresis). This number was then divided by the approximate final volume of the DNA extraction to obtain the number of CFU $\mu l^{-1}$ of DNA extract. In this study, the lowest dilution that produced a significant fluorescence signal contained $81 \mathrm{CFU}$. Since the final volume of the DNA extracts was approximately $160 \mu \mathrm{l}$, the number of
CFU $\mu \mathrm{l}^{-1}$ in this dilution was calculated as $0.5 \mathrm{CFU} \mu \mathrm{l}^{-1}$. Five microliters of DNA were added to each PCR reaction, making the lower detection limit $2.5 \mathrm{CFU} \mu \mathrm{l}^{-1}$. The RQ value for this dilution (2.413 or 2.4) was then established as the threshold RQ for a positive result with the fluorogenic $5^{\prime}$ nuclease assay.

To assess the sensitivity of the assay for dairy samples, dairy enrichments were spiked with enumerated $L$. monocytogenes before incubation for $20 \mathrm{~h}$ at $37^{\circ} \mathrm{C}$. After enrichment, DNA extraction was performed by the Chelex ${ }^{\circledR} 100$ Method 1 protocol. Results indicated a lower detection limit of $5 \mathrm{CFU}$ per $25 \mathrm{~g} \mathrm{ml}^{-1}$ dairy sample after fluorogenic $5^{\prime}$ nuclease PCR and analysis on the TaqMan LS-50B PCR Detection System.

\section{Field study}

A field study was conducted to assess the utility of the developed fluorogenic $5^{\prime}$ nuclease assay for detection of $L$. monocytogenes from dairy plant-generated samples. Two hundred and sixty-six samples were obtained from two California dairy plants, and consisted of a variety of dairy products. Eighty-three of these samples were spiked with varying amounts of $L$. monocytogenes to test detection capabilities. Figure 1 shows the schematic representation of the experimental procedure. In evaluating the results, 10 of the 266 samples were discrepant with respect to culture results, with six false positives and four false negatives. As shown in Table 3, the data produced a $95.2 \%$ sensitivity, $96.7 \%$ specificity, $92.9 \%$ positive predictive value, $97.8 \%$ negative predictive value, and $96.2 \%$ accuracy for the described fluorogenic $5^{\prime}$ nuclease assay using culture verification. Additionally, all samples that produced false positive results were examined further. For each of these samples, any corresponding MOX plate isolates were DNA extracted and tested for cross-reactivity with the fluorogenic 5 ' nuclease assay. However, none of the isolates tested in this manner produced a positive result ( $R Q$ above 2.4), and showed no visible signs of amplification after gel electrophoresis of product.

Gel electrophoresis analysis of all samples tested in the field study was conducted to compare the fluorescent $5^{\prime}$ nuclease assay calls to amplicon presence on agarose gels stained with ethidium bromide. There was 100\% congruence between both methods, with all positive fluorogenic 5' nuclease assay results generating a visible amplicon, and all negative results showing no amplicon on agarose gels for field study samples.

Isolates that produced black colonies on MOX plates from dairy sample enrichments were subjected to fatty acid methyl ester (FAME) analysis to identify these organisms for culture comparisons. This technique also identified organisms that could compete with $L$. monocytogenes in the TSB-LCM medium. Table 4 lists the FAME identification, number of isolates, and predominant food sources of all esculin hydrolysis-positive microorganisms (other than spiked L. monocytogenes) isolated from the field study samples. Bacillus licheniformis was the predominant isolate identified, followed by Bacillus coagulans, Bacillus pumilus, and other Bacillus spp. One Staphylococcus and one Proteus species were also isolated and identified, indicating 


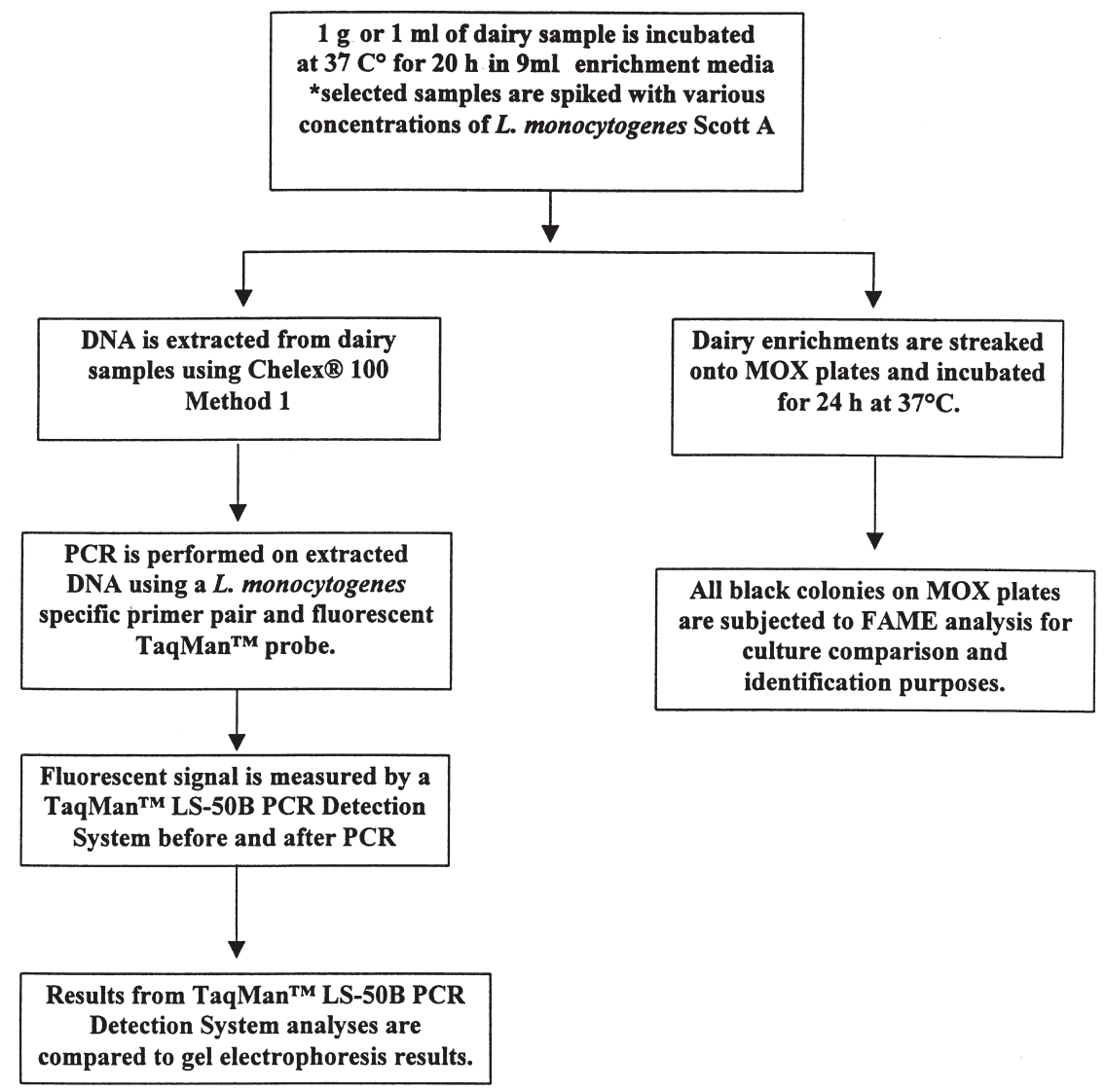

Figure 1 Listeria monocytogenes fluorescent 5' nuclease assay.

Table 3 Sensitivity, specificity, positive predictive value (PPV), negative predictive value (NPV), and accuracy of the Listeria monocytogenes fluorogenic $5^{\prime}$ nuclease assay

\begin{tabular}{lccccc}
\hline $\begin{array}{l}\text { Number of } \\
\text { dairy samples } \\
\text { analyzed }\end{array}$ & Sensitivity & Specificity & PPV & NPV & Accuracy \\
\hline 266 & $95.2 \%$ & $96.7 \%$ & $92.9 \%$ & $97.8 \%$ & $96.2 \%$ \\
\hline
\end{tabular}

Table 4 MOX plate isolate IDs identified by FAME analysis

\begin{tabular}{lcl}
\hline Microbe & $\begin{array}{c}\text { Number of } \\
\text { isolates }\end{array}$ & $\begin{array}{l}\text { Predominant food } \\
\text { sources }\end{array}$ \\
\hline B. licheniformis & 20 & cheese and milk \\
B. coagulans & 11 & cheese and cream \\
B. pumilus & 4 & milk and yogurt \\
B. amyloliquefaciens & 3 & cheeses \\
B. atrophaeus & 1 & swiss cheese \\
B. brevis & 1 & milk \\
B. cereus & 1 & cream \\
Staph. epidermis & 1 & cream \\
Proteus mirabilis & 1 & swiss cheese \\
\hline
\end{tabular}

that these organisms could proliferate in TSB-LCM and compete with L. monocytogenes during enrichment.

\section{Discussion}

The described fluorogenic 5' nuclease assay was successful in analyzing low numbers of artificially spiked L. monocytogenes in dairy enrichments within $24 \mathrm{~h}$ or less. An enrichment medium formulation and a DNA extraction protocol were designed and optimized for use with this fluorogenic 5' nuclease assay. Development of the enrichment medium for this study involved the investigation of different non-fluorescent selective agents that inhibited the growth of competing flora, while allowing for proliferation of low numbers of $L$. monocytogenes (unpublished data). DNA extraction studies evaluated eight protocols of known utility for their efficiency in extracting $L$. monocytogenes DNA from dairy enrichments for use with the fluorogenic 5' nuclease assay. Three of the methods (Chelex 1, GuSCN 3, and EnviroAmpl) performed well with a 100\% positive and negative predictive value for the study (Table 2) [8]. However, the Chelex ${ }^{\circledR} 100$ Method 1 was chosen for further applications because it was easier, less toxic, and more economical than the other two procedures. Incorporation of the Bio 101 Spin Filter ${ }^{\circledR}$ device further enhanced the reproducibility and reliability of this method by removing fluorescent residue and possible PCR inhibitors from the extracts. Evidence for the effectiveness of the extraction 
method was apparent as RQ values of most negative dairy samples deviated by only \pm 0.4 RQ points from the no template controls. PCR inhibition was also minimal, supported by the low number of false negative results obtained in the field study (Table 3). The extraction method proved to be reliably accurate for most samples run through the fluorogenic 5' assay, given the wide variety of complex dairy samples with high lipid and protein contents analyzed (ie butter, buttermilk, raw milk, and yogurt).

Optimization of the outlined Listeria monocytogenes fluorogenic 5' nuclease assay included both sensitivity and specificity studies. Sensitivity studies involving pure cultures and L. monocytogenes spiked dairy enrichments demonstrated that the assay was reliably sensitive, with lower detection limits below 10 CFU under both conditions. With these data, a positive threshold RQ value of 2.4 and above was designated for the analysis of dairy enrichment extracts for this assay. Figure 2 shows the linear relationship of CFU/PCR and RQ values for sensitivity studies performed on pure cultures of L. monocytogenes. The graph demonstrates the quantitative nature of the assay with pure culture extracts. Sensitivity of the complete assay utilizing dairy enrichments was performed with a lower detection limit determined at 5 CFU per $25 \mathrm{~g} \mathrm{ml}^{-1}$ of dairy sample. Analyses involving post-enrichment spiked dairy samples were not performed in this study, but are presently being tested with a variety of dairy products.

Assay specificity tests performed on 60 bacterial species other than L. monocytogenes showed cross-reactions with five organisms (Table 1). However, only one of the five organisms (Listeria grayi) was able to proliferate in the enrichment medium employed within $24 \mathrm{~h}$. Although this could potentially be a source of false positive designations, this organism was not isolated from any of the dairy products evaluated thus far, and has never been isolated in our studies involving environmental samples from dairy production environments [7]. Other studies suggest that Listeria grayi is very rarely isolated from food sources [17]. Cross-reactivity with DNA targets of other species may have been due to large or optimal amounts of DNA present in the PCR mix causing non-specific amplification. More

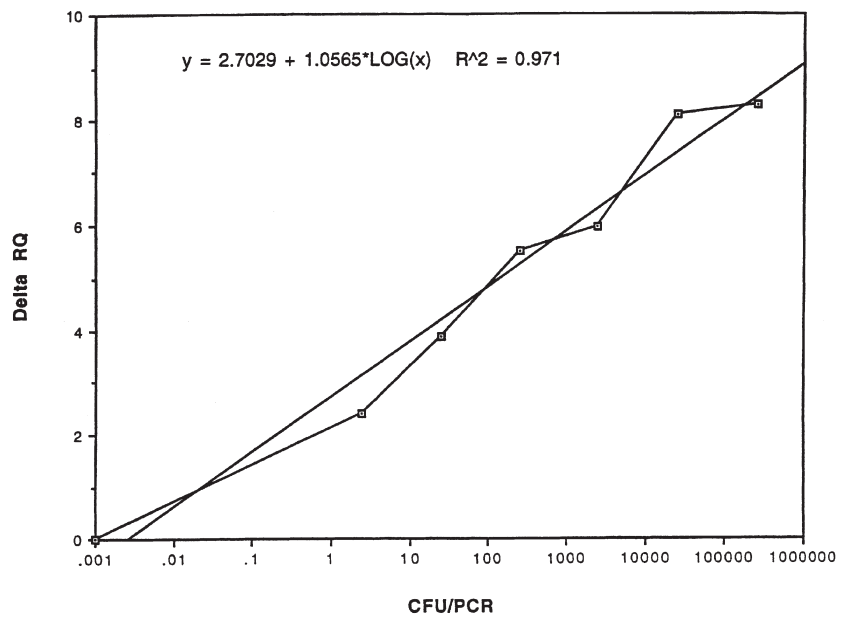

Figure 2 Detection of $L$. monocytogenes pure culture extracts using the fluorogenic 5' nuclease assay. stringent thermocycling conditions are presently being investigated to reduce or eliminate all cross-reactivity with this fluorogenic $5^{\prime}$ assay.

The experimental protocol outlined in Figure 1 describes the steps taken to test the assay in a field study utilizing 266 dairy samples from two different California dairy production facilities. The two segments of the field study involved analysis of dairy enrichment extracts with the $L$. monocytogenes fluorogenic $5^{\prime}$ nuclease assay and simultaneous culture comparisons for each sample. Since the culture comparison procedure is not completely selective for L. monocytogenes, all isolates from MOX plates exhibiting esculin hydrolysis were identified by fatty acid methyl ester (FAME) analysis. This analysis also served another purpose: to identify organisms other than L. monocytogenes present in dairy samples that had the ability to proliferate and compete with L. monocytogenes in the enrichment media. Forty-three esculin hydrolysis-positive isolates (other than L. monocytogenes) from MOX plates were obtained and identified by FAME analysis (Table 4). Fortyone of these organisms were identified as $B$. licheniformis and other Bacillus spp. Some of the isolates (those from false positive dairy enrichments) were DNA extracted and analyzed by the fluorogenic $5^{\prime}$ nuclease assay. None of the isolates tested in this manner, however, produced positive responses with the fluorogenic 5' assay or visible evidence of amplification on agarose gels.

When compared to culture results, the fluorogenic 5' nuclease assay performed within and above the statistical percentages of other described methods of detection (Table 3) [10]. Especially noteworthy is the method's negative predictive value (97.8\%), which gives the confidence level of a negative call as compared to standard culture techniques. This value is crucial for the food and dairy industry and consumer safety. The four false negative result designations that were obtained were from cheese (1), cottage cheese curd (2), and buttermilk (1) dairy sample enrichments. Three out of these four false negative samples were spiked with low numbers of CFU (50-60) before enrichment procedures, suggesting that low numbers of cells after enrichment may have contributed to a false negative call. PCR inhibitors could have also been present in these DNA extracts, with amplification inhibition being more pronounced with low numbers of target sequences in the PCR reactions.

All false positive results obtained revealed evidence of amplification on agarose gels. This indicated that the target sequence was present, and that the increase in fluorescence was not a consequence of inherent fluorescence in the DNA extracts. These false positive results could have been due to cross-contamination during the extraction procedure, because high, low, and non-spiked enrichment samples were extracted simultaneously. Primer and probe crossreactivity could have occurred with organisms other than L. monocytogenes in the enrichments and DNA extracts. Another possibility is that this assay may be more sensitive than culture methods, detecting low numbers of L. monocytogenes naturally present in dairy samples.

In conclusion, the proposed fluorogenic 5' nuclease assay for the detection of $L$. monocytogenes in dairy products is a sensitive method with high-throughput capabilities that 
can be completed within $24 \mathrm{~h}$ of sampling. The fluorescent detection format of the assay also eliminates the complications of subjective gel electrophoresis analysis. Verification of the method with culture comparisons on 266 dairy samples gave statistical percentages of sensitivity, specificity, positive predictive value, negative predictive value, and accuracy well above $90 \%$, which compares favorably to other L. monocytogenes detection methods [10].

\section{Acknowledgements}

This research was supported by the California Dairy Foods Research Center through funding of the California Dairy Research Foundation and Dairy Management. Special acknowledgement goes to Dr Phillip Tong for his assistance with setting up sample collections. We also thank Kristen De Bord, Chad Green, and the laboratory support staff at EBI for their efforts towards the goals of this project.

\section{References}

1 Bassler HA, SJ Flood, KJ Livak, J Marmaro, R Knorr and CA Batt. 1995. Use of a fluorogenic probe in a PCR-based assay for the detection of Listeria monocytogenes. Appl Environ Microbiol 61: 37243728.

2 Boom R, CJ Sol, MM Salimans, CL Jansen, PM Dillen and JV Noordaa. 1990. Rapid and simple method for the purification of nucleic acids. J Clin Microbiol 28: 495-503.

3 Candrian U. 1995. Polymerase chain reaction in food microbiology. J Microbiol Meth 23: 89-103.

4 Cano RJ, C Oste, D Norton and A Inzunza. 1995. Polymerase chain reaction assay coupled with fluorescent detection on microwell plates for Listeria monocytogenes in foods. J Food Prot 58: 614-617.

5 Chen S, A Lee, M Griffiths, C Larkin, CT Yamashiro, R Behari, C Paszko-Kolva, K Rahn and SA DeGrandis. 1997. The evaluation of a fluorogenic polymerase chain reaction assay for the detection of Salmonella species in food commodities. Int J Food Microbiol 33: 239-250.

6 Cooray K, T Nishibori, H Xiong, T Matsuyama, M Fujita and Mitsuyama. 1994. Detection of multiple virulence-associated genes of Listeria monocytogenes by PCR in artificially contaminated milk samples. Appl Environ Microbiol 60: 3023-3026.
7 Cox T, C Green, J Saldana, SJ Flood, C Paszko-Kolva and RJ Cano. 1997. Development of a flurogenic $5^{\prime}$ nuclease assay for the rapid detection of Listeria spp in dairy environmental samples. Poster session, ASM Annual Meeting, Miami, FL.

8 Cox T, R Behari, SJ Flood, CT Yamashiro, C Paszko-Kolva and RJ Cano. 1996. Evaluation of rapid DNA extraction methods for the detection of Listeria monocytogenes in dairy products using the TaqMan Sequence Detection System. Poster session, IAMFES Annual Meeting, Seattle, WA.

9 De Lamballerie X, C, Zandotti, C Vignoli, C Bollet and P de Micco. 1992. A one-step microbial DNA extraction method using 'Chelex 100’ suitable for gene amplification. Res Microbiol 143: 785-790.

10 Flanders KJ, TJ Pritchard and CW Donnelly. 1995. Enhanced recovery of Listeria from dairy plant processing environments through combined use of repair enrichment and selective enrichment/detection procedures. J Food Prot 58: 404-409.

11 Golsteyn Thomas E, R King, J Burchak and V Gannon. 1991. Sensitive and specific detection of Listeria monocytogenes in milk and ground beef with the polymerase chain reaction. Appl Environ Microbiol 57: 2576-2580.

12 Goodwin D and S Lee. 1993. Microwave miniprep of total genomic DNA from fungi, plants, protists, and animals for PCR. Biotechniques 15: 438-444.

13 Lantz P, F Tjerneld, E Borch, B Hahn-hagerdal and P Radstrom. 1994. Enhanced sensitivity in PCR detection of Listeria monocytogenes in soft cheese through use of an aqueous two-phase system as a sample preparation method. Appl Environ Microbiol 60: 3416-3418.

14 Livak K, SJ Flood, J Marmaro, W Giusti and K Deetz. 1995. Oligonucleotides with fluorescent dyes at opposite ends provide a quenched probe system useful for detecting PCR product and nucleic acid hybridization. PCR Meth Applic 4: 357-362.

15 Niederhauser C, U Candrian, C Hofelein, M Jermini, HP Buhler and J Luthy. 1992. Use of polymerase chain reaction for detection of Listeria monocytogenes in food. Appl Environ Microbiol 58: 1564-1568.

16 Paisley R. 1997. Sample handling. In: MIS Whole Cell Fatty Acid Analysis by Gas Chromatography Training Manual. D1-D22, MIDI Inc, Newark, Delaware.

17 Rocourt J and H P R Seeliger. 1985 Distribution des especes du genre Listeria. Zentrasbl Bakteriol Parasitenkd Infektionskr Hyg, Abt 1 Orig Reihe A 259: 317-330.

18 Schuchat A, B Swaminathan and C Broome. 1991. Epidemiology of human Listeriosis. Clin Microbial Rev 4: 169-183.

19 Witham PK, CT Yamashiro. KJ Livak and CA Batt. 1996. A PCRbased assay for the detection of Escherichia coli Shiga-like toxin genes in ground beef. Appl Environ Microbiol 62: 1347-1353. 